Traum und Trauma 


\section{Traum und Trauma vom Schlaf der Vernunft}

Spanien zwischen Tradition und Moderne und die Gegenwelt Francisco Goyas 
Die Deutsche Bibliothek - CIP-Einheitsaufnahme

Dittberner, Susanne: Traum und Trauma vom Schlaf der Vernunft : Spanien zwischen Tradition und Moderne und die Gegenwelt Francisco Goyas / Susanne Dittberner. - Stuttgart ; Weimar : Metzler, 1995 ISBN 978-3-476-01303-3

ISBN 978-3-476-01303-3

ISBN 978-3-476-03597-4 (eBook)

DOI 10.1007/978-3-476-03597-4

Dieses Werk einschließlich aller seiner Teile ist urheberrechtlich geschützt. Jede Verwertung außerhalb der engen Grenzen des Urheberrechtsgesetzes ist ohne Zustimmung des Verlages unzulässig und strafbar. Das gilt insbesondere für Vervielfältigungen, Übersetzungen, Mikroverfilmungen und die Einspeicherung und Verarbeitung in elektronischen Systemen.

(C) 1995 Springer-Verlag GmbH Deutschland Ursprünglich erschienen bei J.B. Metzlersche Verlagsbuchhandlung und Carl Ernst Poeschel Verlag GmbH in Stuttgart 1995 


\section{INHALT}

EINLEITUNG $\ldots \ldots \ldots \ldots \ldots \ldots \ldots \ldots$

\section{ERSTES KAPITEL: VISION UND TRAUMA - DAS HABSBURGISCHE SPANIEN}

1. Gegenwart der Geschichte . . . . . . . . . . . . . . 13

2. Expansion und Desintegration . . . . . . . . . . . . . . . 17

3. Modell der unbeschränkten Souveränität: Die Inquisition . . . . . . . 26

4. Hybris und Scheitern der Eroberungspolitik . . . . . . . . . . . . . 37

5. Die Ökonomie der Verschwendung . . . . . . . . . . . . . . . . . . . . . . 43

6 . Adel und Exklusion . . . . . . . . . . . . . . . . . . 46

7. Der Imperativ der Ehre . . . . . . . . . . . . . . . . . . 53

8. Das Leiden an der Ehre und der Pícaro . . . . . . . . . . . . . 56

9. Die Schwarze Legende . . . . . . . . . . . . . . . . . . 61

10. Velázquez und der Traum der Epoche . . . . . . . . . . . . . 64 Venus und Maja (68)

\section{ZWEITES KAPITEL: LICHT UND SCHATTEN DER BOURBONISCHEN MODERNISIERUNG}

1. Die neue Infrastruktur . . . . . . . . . . . . . . . . 72

a) Gelingen und Scheitern der Zentralisierung . . . . . . . . . . 72

b) Regalismus . . . . . . . . . . . . . . . . . . . . . 73

c) Steuern und merkantilistische Logik . . . . . . . . . . . . . . 75

d) Die $»$ Adern $«$ der Zirkulation . . . . . . . . . . . . . . . . . . 78

2. Die Fruchtbarkeit des Bodens und der Menschen - Landwirtschaftsreformen und demographische Regulation . . . . . . . . . . . . 79

3. Merkantilismus, Physiokratismus und die eigenwillige Synthese des Jovellanos . . . . . . . . . . . . . . . . . . . . . . . 89

4. Handelsbilanz, Handelsprivilegien und amigos del país . . . . . . . 95

5. Glanz und Elend der Manufaktur . . . . . . . . . . . . . . . . . . 105

6. Der Prozeß der Disziplinierung und der Traum der Vernunft . . . . 111

7. Die Diskurse . . . . . . . . . . . . . . . . . . . . 120 
a) Die Rezeption der philosophes. Rückschläge und Perspektiven . . . 120

b) Zwischen Sysiphos und Prometheus: Heroen der Presse und der Satire . . . . . . . . . . . . . . . . . . . . . . . 127

8. Konkurrenz der Apotheosen - Tiepolo und Mengs . . . . . . . . . . . 129

9. Die Konkurrenz der Lebensstile . . . . . . . . . . . . . . . . . . . . . 134

a) Die Petimetres: Galanterie und Feminisierung der Sitten . . . . . 134

b) Die praktische Erfindung des auténtico ser: Der Majismo . . . . . . 139

c) Die Ambivalenz des Majismo und der Aufstand gegen Esquilache . 145 Goyas Motín de Esquilache (149)

10. Die Hispanisierung der Bourbonen . . . . . . . . . . . . . . . . . . 150

11. Renaissance der schwarzen Legende und Beginn eines spanischen Risorgimento: Die Masson-Affaire . . . . . . . . . . . . . . . 152

\section{DRITTES KAPITEL: GOYAS ANFÄNGE}

1. Spiele am Ufer des Manzanáres . . . . . . . . . . . . . . . . . . 159

a) Die Zeit der unbeschwerten Launen . . . . . . . . . . . . . . . 159

b) Die innere Abkehr von der Manufaktur . . . . . . . . . . . . . . . 166

c) Die Masken der Zerstreuung: Das Blindekuhspiel . . . . . . . . . . 171

2. Vom »aragonesischen Dorf« zur Teppichmanufaktur - Biographie und Legende . . . . . . . . . . . . . . . . . . . . . . . . . . . 179

a) Zaragoza, Rom und Madrid . . . . . . . . . . . . . . . . . . . . 179

b) Der Streit um El Pilar: Goyas Begriff der Originalität und künstlerischen Wahrheit . . . . . . . . . . . . . . . . 188

c) Akademiker, Gönner und ilustrados . . . . . . . . . . . . . . . 191

\section{VIERTES KAPITEL: SPANIEN} UND DAS REVOLUTIONÄRE FRANKREICH

1. Die Restauration der Kreuzzugsidee . . . . . . . . . . . . . . . . . . 199

2. Der Legitimitätsverlust der Krone . . . . . . . . . . . . . . . . . 207

a) Godoys aufgeklärtes Engagement und seine Grenzen . . . . . . . . 207

b) Die Sexualisierung der Politik . . . . . . . . . . . . . . . . . 215

c) Das Trauma Godoy und der Tigersprung in die Geschichte . . . . . 219

d) Pan y toros . . . . . . . . . . . . . . . . . . . . . . . . . . . . . . . . . . 220

3. Spiegel der Ohnmacht der Macht . . . . . . . . . . . . . . 225

a) Der Glanz des Banalen: Das Familienporträt I . . . . . . . . . . . 225

b) Maler, Muse und Macht: Las Meninas . . . . . . . . . . . . . . 228

c) Die Drohung der Geisterwelt: Radierungen nach Velázquez . . . . 234

d) Verschwörung der Diener: Die Familie des Infanten . . . . . . . . 238

e) Kunst als Selbstaffirmation: Das Atelierbild . . . . . . . . . . . . . 241

f) Das Gefängnis des Souveräns und die Souveränität der Kunst: Das Familienporträt II . . . . . . . . . . . . . . . . . . . . . . . . 243 
4. Die Suche nach dem Ursprung und die Konstruktion der

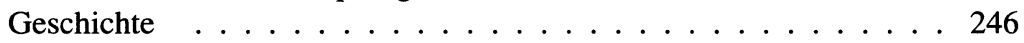

5. Das Kabinett der Intellektuellen . . . . . . . . . . . . . . . . 249

6. Die Eule der Minerva und der Traum der Vernunft . . . . . . . . . . . 256

a) Freundschaftsbild und Staatsporträt . . . . . . . . . . . . 256

b) Goyas Melancholia: Das Bildnis Jovellanos' und Capricho 43 . . . 260

7. Fin de siècle und Abgesang . . . . . . . . . . . . . . . . . . . 269

\section{FÜNFTES KAPITEL: DIE KRANKHEIT DES HERZENS UND DER VERNUNFT - DIE VORGESCHICHTE DER CAPRICHOS}

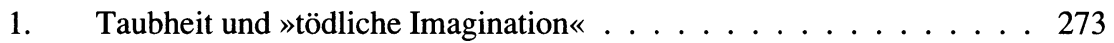

a) Die Reise . . . . . . . . . . . . . . . . . . . . . . . 273

b) Der Zauber des Lunaren: Die Kabinettbilder . . . . . . . . . . . 277

2. Das Universum des Begehrens . . . . . . . . . . . . . . . 283

a) Goya und die Cayetana . . . . . . . . . . . . . . . . . 283

b) Fest der Nymphen: Das Sanlúcar Album (Album A) . . . . . . . . 286

c) Femme-Fatale, Masken und Wortspiele: Das Madrider-Album (Album B) . . . . . . . . . . . . . . . . . . . . . . . . 288

3. Das Universum der Hexen: Moratín, Goya und die Sueños . . . . . . 297

a) Die Hexen von Zugarramurdi . . . . . . . . . . . . . . . . . 297

b) Metamorphosen des Schrecklichen: Das Erhabene und das

Geschmacklose . . . . . . . . . . . . . . . . 303

Die Liebhaber des Häßlichen und der sublime Schauer (303)-

Grotesken für die Alameda (306) - Die Hexen der Sueños (309)

c) Die Celestina und der Traum von Lüge und Wankelmut . . . . . . . 311

\section{SECHSTES KAPITEL: TÄUSCHUNG UND ENTTÄUSCHUNG - DIE CAPRICHOS}

1. Nobilitierung des Unvollkommenen: Die Annonce . . . . . . . . 318

2. Der beteiligte Beobachter . . . . . . . . . . . . . . . . 323

3. Die Kluft zwischen den Geschlechtern: Der erste Teil

der Caprichos . . . . . . . . . . . . . . . . . . . . . . 324

Wahl zwischen zwei Übeln (324) - Begegnungen auf dem

Paseo (326) - Die vornehmen Kokotten (329) - „Sabbat der

Zivilisation« (331) - Männliche Laster (332) - Das Geschlechter-

verhältnis als Ausdruck der verkehrten Welt (334) - Die Kette

der Verstrickungen (335) - Gewalt und Leidenschaft (337) -

Ursachen und Folgen (339) - Goyas Aufklärungstheorie (341)

4. Die Schule der Esel - Ein Zwischenspiel . . . . . . . . . . . . . . 341

5. Das Phantasma des Sozialen: Der zweite Teil

der Caprichos . . . . . . . . . . . . . . . . . . . . . . 344 
Geistiges und geistliches Elend: Die antiklerikalen Blätter

(344) - Mißstände der Stände (348) - Die negative Synthesis (349)

6. Bildsprache und Sprachbilder

\section{SIEBTES KAPITEL: UNABHÄNGIGKEITSKRIEG UND RESTAURATION}

1. Coup d'Etat und Volkskrieg . . . . . . . . . . . . 355

a) Der Sturz Godoys . . . . . . . . . . . . . . . . . . 355

b) Die messianische Dimension des Aufstands . . . . . . . . . 359

c) Die Guerilla . . . . . . . . . . . . . . . . . . . . 362

2. Die Intellektuellen und die Macht . . . . . . . . . . . . . . . 366

a) Spaltung der ilustrados: afrancesados und liberales . . . . . . . . 366

b) Der Widerstand des ancien régime und die Anfänge des bürgerlichen Nationalismus . . . . . . . . . . . . . . . . . 371

3. Triumph und Scheitern der spanischen Demokratie . . . . . . . . . 373

a) Juntas, Zentraljunta und Cortes . . . . . . . . . . . . . . . 373

b) Restauration, pronunciamientos und Riegos Sieg . . . . . . . . . . 378

c) Die Spaltung der liberales und die Herrschaft des Würgengels .................... 381

\section{ACHTES KAPITEL: GOYA ZWISCHEN RÜCKZUG} UND ENGAGEMENT

1. Goyas innere Emigration . . . . . . . . . . . . . . . 385

2. Die zweite Generation der Zeichenalben . . . . . . . . . . . . . . . . 387

3. Die Ereignisse des zweiten Mai und Goyas Reise nach

Zaragoza . . . . . . . . . . . . . . . . . 391

4. Überleben und Leidenschaft . . . . . . . . . . . . . . . . . . . . 393

5. Goya und die Restauration . . . . . . . . . . . . . . . . . . . . . 399

6. Das schwarze Loch der Macht - die Philippinenkompanie . . . . . 402

7. Rembrandts Licht und die Schatten der Quinta . . . . . . . . . . . 406

8. Flucht und Exil . . . . . . . . . . . . . . . . . . . . . . . . . 409

NEUNTES KAPITEL: DIE SCHRECKEN DES KRIEGES LOS DESASTRES DE LA GUERRA

1. Der Konflikt des Zeitzeugen _. . . . . . . . . . . . . . . 415

2. Gesichter des Krieges . . . . . . . . . . . . . . . . . . . 421

Nada-Nichts (421) - Betten des Todes (422) - Schändungen (425) Flucht (432) - Todesarten (434) - Die Erschießung der Aufständischen (442) 
3. Das stille Sterben: Die Hungerszenen . . . . . . . . . . . . . 450 Plünderungen (450) - Das Antlitz des Hungers (451)

4. Caprichos Enfáticos . . . . . . . . . . . . . . . . . . 457

\section{ZEHNTES KAPITEL: DIE SPIEGEL DES WIDERSINNS -} GOYAS DISPARATES

1. Die Schwierigkeiten der Deutung . . . . . . . . . . . . . . . . . . . . . . . . 463

2. Verfremdung und Widersinn . . . . . . . . . . . . . . . . . 467

Bildmetaphern der Angst (467) - Bilder der sozialen und

geschlechtlichen Verstrickung (473) - Die Welt des Absurden (479)

3. Sinn im Widersinn - Der Abgrund der Moderne . . . . . . . . . . . 486

LITERATUR . . . . . . . . . . . . . . . . . . 493

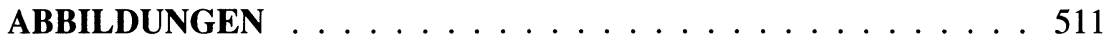

